
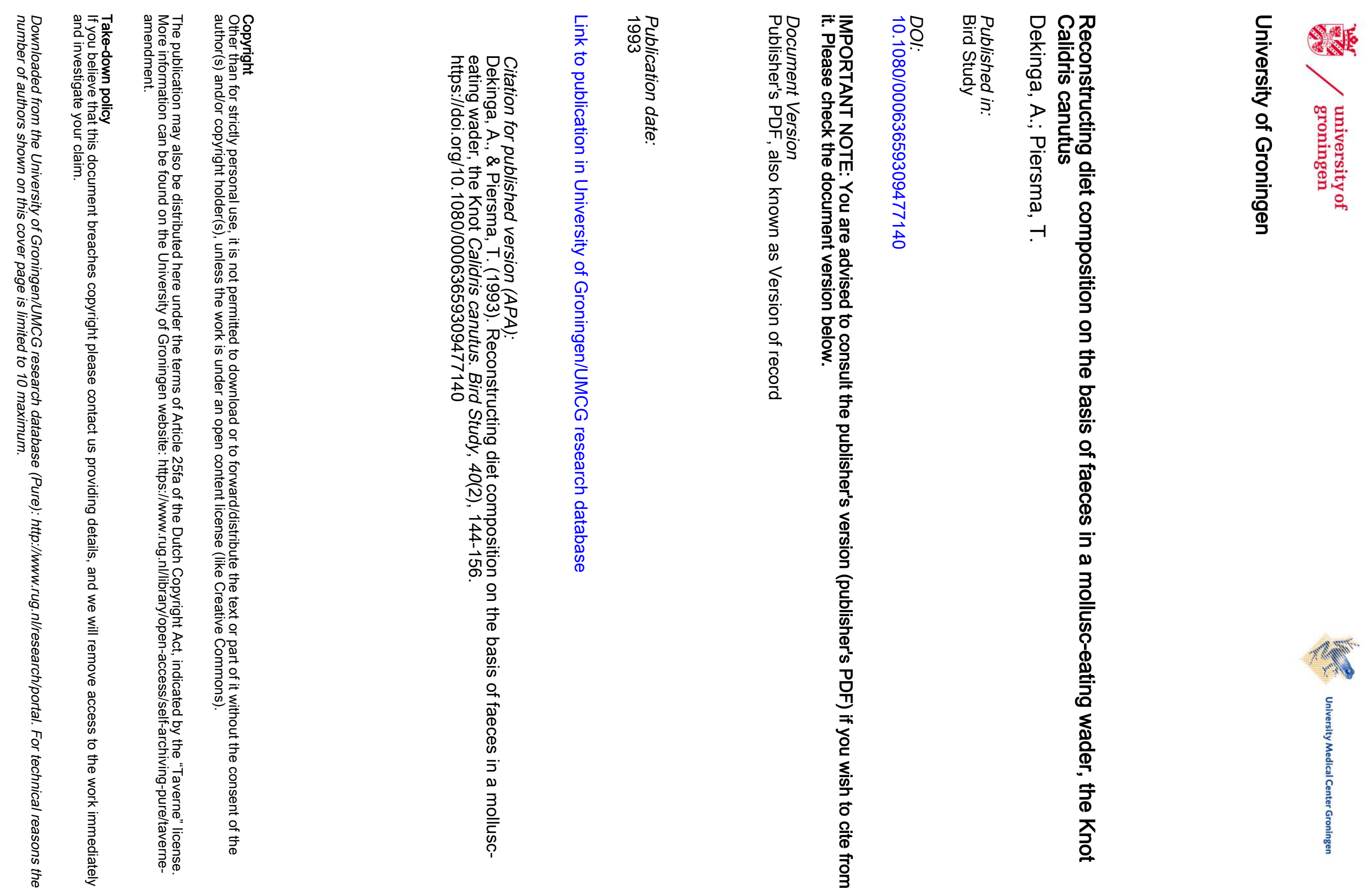


\title{
Reconstructing diet composition on the basis of faeces in a mollusc-eating wader, the Knot Calidris canutus
}

\author{
A. DEKINGA and T. PIERSMA Netherlands Institute for Sea Research \\ (NIOZ), PO Box 59, 1790 AB Den Burg, Texel and Zoological Laboratory, \\ University of Groningen, PO Box 14,9750 AA Haren, The Netherlands
}

\begin{abstract}
Methods are described to assess the molluscan diet of Knots feeding on intertidal flats in western Europe from their faecal output. The size distributions of two common bivalve prey, Macoma balthica and Cerastoderma edule, can be estimated from the heights of shell hinges retrieved from droppings. The average ingested size of the tiny mudsnail Hydrobia ulvae can be reconstructed from partially broken shells. Diet composition in terms of biomass can be estimated by a two-step procedure. First, the diet composition in terms of ash or shell mass is estimated on the basis of the sieved mass of droppings. The application of the site-, season- and size-specific ratios of biomass/shell mass or biomass/ash mass then provides a breakdown of diet with respect to biomass. An exploratory field study in the Wadden Sea showed that measurable fragments in (rarely encountered) regurgitates overestimate prey size. According to the faecal analysis, there was a seasonal change in diet from bivalves to mudsnails with the approach of winter. In combination with field measurements of defecation rates, the outlined methodology may allow the use of droppings as indicators of intake rates.
\end{abstract}

$\mathrm{T}$ he distribution of birds is invariably constrained by the abundance of critical resources, of which food is one of the most important. A first step in elucidating the relationships between birds and their food is to determine what they are feeding on, methods for which can vary between just observing free-living birds foraging and killing them for gut analyses. Foraging studies are easiest in bird species that live in open and accessible habitats, with small numbers of prey species of sizes large enough to be visible when ingested, and for which abundance and availability parameters which can easily be measured. Waders are widely recognized as such a group, and this may explain why they feature so prominently in the foraging literature. ${ }^{1-7}$ Among the small waders, the feeding ecology of Knots Calidris canutus has perhaps received most

Correspondence: Theunis Piersma, Netherlands Institute for Sea Research (NIOZ), PO Box 59, 1790 AB Den Burg, Texel, The Netherlands. attention. ${ }^{8-13}$ Although the prey organisms of Knots are sometimes too small to be observed when ingested, ${ }^{14}$ hard-shelled molluscs usually dominate their diet. Such molluscs are ingested whole, their crushed remains ending up in droppings and regurgitates. This material has frequently been used to describe the diet of Knots ${ }^{9-12,15}$ and related wader species. ${ }^{16-18}$

Our study belongs to a growing number of methodological papers which aim to analyse the extent to which recognizable prey remains in faeces, pellets or enforced regurgitates provide an unbiased picture of the diet. ${ }^{19-25}$ Throughout we were motivated by the belief that the value of the conclusions drawn from field studies will be proportional to the efforts made to calibrate their methodologies.

To evaluate our laboratory trials, and to illustrate the results to be obtained by the approach advocated, we briefly present an analysis of faecal samples and regurgitates collected during one autumn-season of fieldwork in the Wadden Sea. 


\section{METHODOLOGICAL RATIONALE}

The problem is to estimate accurately both the size distribution of the prey species and the proportions of the diet attributable to different prey species. As an indicator of profitability to the predator, prey size is generally the most relevant parameter because it is usually correlated with prey availability. ${ }^{26-30}$ It is the relative contributions in terms of biomass that indicate the importance of different prey types as food.

Recognizable and measurable prey fragments found in the faeces were used to estimate ingested size distributions (Methods section: 'Predicting shell size from measurable fragments'). However, in view of the great variation in the proportion of measurable shell fragments retrieved from the droppings, the biomass contribution of each prey species in the diet was derived from weighed samples of shell fragments sorted by species (Methods section: 'Faecal analysis'). Additionally, in view of the variable biomass of the molluscs involved (in relation to shell size, geographical location and season), the biomass intake of Knots was estimated using much more constant 'markers' (shell or ash mass) estimated from sieved shellfragment mass, and the appropriate empirical ash/biomass or shell/biomass quotients (Results section: 'Estimating diet composition'). A number of scaling and weighting problems are identified and resolved.

\section{METHODS}

\section{Feeding experiments}

Feeding experiments were carried out to simulate the feeding of Knots on natural prey types under controlled conditions where the characteristics and quantity of both intake and ejecta could be accurately quantified. Feeding experiments took place in climate rooms. In order to ensure a range in the levels of daily food intake, a variety of air temperatures $(1.5,13,19$ and $33^{\circ} \mathrm{C}$ ) was offered. The experimental cages measured $50 \times 50 \times 50 \mathrm{~cm}$. The bottoms of the cages were covered with a plastified wire mesh through which droppings and regurgitates fell. In this way the trampling of excreta by birds was avoided, and it was easy to distinguish droppings from regurgitates. We gave a 13-hr day (bright light from 07.00 to 20.00 hours, dim light to simulate starlight at night). Fresh water was always available ad libitum.

Experiments were carried out with four natural prey types: the three bivalve species Edible Mussel Mytilus edulis (57 experiments; 8 different birds), Edible Cockle Cerastoderma edule ( $2 ; 2$ birds), Balthic Tellin Macoma balthica (7; 3 birds), and the Mudsnail Hydrobia ulvae (16; 3 birds). To extend the range of observations, the subtidally living bivalve Spisula subtruncata was opportunistically used in one series of 12 experiments ( 4 birds). A total of 12 different individual Knots was used in the experiments. The variation in the number of trials per prey type is a consequence of the difficulty of collecting sufficient amounts of some natural prey. The birds were not fed grit.

Cerastoderma, Macoma and Hydrobia were collected at a variety of localities in the Dutch Wadden Sea, Mytilus was scraped from the small basalt piers along the North Sea coast of Texel, whereas Spisula was fished just offshore the Dutch coast in the southern North Sea. During storage of up to 4 weeks, the molluscs were kept in basins with cold $\left(1.5^{\circ} \mathrm{C}\right)$ running sea water. They were not fed, but the low water temperature ensured minimal loss of body tissue.

Droppings and regurgitates (pellets) were collected separately from the floor below the mesh. Pellets occurred only rarely. Visual observations showed that they were usually voided after birds had taken a drink, which explained why the regurgitates were often found in the water container.

Diet reconstruction in biomass terms means that we have to estimate the 'ingested mollusc meat equivalent' (the organic cuticle of mollusc shells is hardly, if at all, digestible; T. Piersma, unpubl. data). In bivalves the meat (soft body tissue) is easily separated from the shell, and therefore the biomass (ash-free dry mass) in the meat (henceforth indicated with $\left.\mathrm{AFDM}_{\text {meat }}\right)$ and in the shell (AFDM $\mathrm{Ahell}_{\text {she }}$ ) are easily measured. In small gastropods this is impossible and biomass is therefore expressed in the total ash-free dry mass $\left(\mathrm{AFDM}_{\text {total }}\right)$. For each series of feeding trials the characteristics of the food on offer, such as length-dependent fresh mass, dry mass, AFDM shell and $\mathrm{AFDM}_{\text {meat }}$ (or $\mathrm{AFDM}_{\text {total }}$ ) and ash masses, were determined. In the bivalves, $5-10$ specimens per length class were freshly weighed and the 
meat separated from the shell after a short submersion ( $5 \mathrm{~s}$ ) in boiling water (see Zwarts ${ }^{31}$ for remarks on this methodology). For both the shell and the meat fractions, dry mass (after drying to constant mass at $55-60^{\circ} \mathrm{C}$ ), ash mass (after incinerating the dry material at $550^{\circ} \mathrm{C}$ ) and ash-free dry mass (derived by subtraction) were measured. Samples of Hydrobia underwent the procedure without separating the meat from the shell.

Each of the 94 feeding trials consisted of an offering of one food type at 13.15 hours. The food was taken away the following morning at 09.00 hours, leaving the birds $4 \mathrm{hr}$ to empty their guts before the experiment ended at 13.00 hours. (Successive experiments with differently coloured prey, e.g. dark-shelled Mytilus and light-shelled Macoma, suggest that only very little ( $<1 \%$ of a daily portion) shell material remains in the gut after $4 \mathrm{hr}$ of emptying, hence providing an unlikely bias.) We determined the size distribution (in addition to the characteristics mentioned above) of both the food on offer and that left uneaten.

Because many of the Knots had been living for some time in captivity during which they were fed with trout food pellets, they usually took a few days to adjust to a new food type. As a rule, we gave them at least 4 days' experience of a novel food type before conducting the experiments. However, one experimental animal joined the sessions immediately after arrival from the mudflats in the Dutch Wadden Sea with a damaged wing. This bird was allowed to continue feeding on its natural prey Macoma.

\section{Predicting shell size from measurable fragments}

The only measurable parts of Macoma and Cerastoderma in the faeces of Knots were their tops. We constructed predictive equations to estimate shell length in these two bivalves by measuring the hinge+top (or hinge only) height as outlined in Fig. 1. No such parts could be identified in Mytilus (contra the studies on Common Eiders Somateria mollis$\operatorname{sim} a^{32,33}$ ). All hinges of Spisula in the Knot droppings were broken and the size distribution of ingested shells could not be reconstructed. (Fortunately this subtidal species does not form part of the natural food spec- trum of Knots.)

In Hydrobia broken shells from which the tops had disappeared were used, by measuring the width of the last whorl and relating width to total shell height. However, although apparently fully digested (contra Cadée's ${ }^{34}$ findings for Hydrobia-eating Shelduck Tadorna tadorna, droppings from which contained living snails), not all individual shells were fragmented during digestion. We therefore also measured the length of intact shells in the droppings.

Bivalve lengths were measured with calipers; hinge heights and Hydrobia widths and heights were measured under a binocular microscope with an eye-piece micrometer.

\section{Faecal analysis}

After drying at $55-60^{\circ} \mathrm{C}$, faeces were weighed and sieved over a $0.3-\mathrm{mm}$ mesh to remove sand, organic material and the smallest shell fraction. The particles remaining on the sieve consisted almost entirely of shell fragments and were weighed (this fraction will henceforth be called $\mathrm{DM}_{\mathrm{drop}}$ ). The measurable hinges of Macoma and Cerastoderma and the broken or intact Hydrobia were selected and measured. In some cases the number of measurable items was so large that weighed sub-samples were used to reconstruct the composition of the faeces. Apart from determining the size of measurable fragments, sub-samples or the entire amount of $\mathrm{DM}_{\text {drop }}$ were sorted into mollusc species and weighed, yielding values for species-specific partial-DM $\mathrm{drop}_{\text {. }}$

\section{Fieldwork}

Knots were observed and samples of their droppings and regurgitates collected on the flats after feeding flocks had left, and on the beach roosts near the island of Griend, located in the middle of the western Dutch Wadden Sea $\left(53^{\circ} 08^{\prime} \mathrm{N}, 4^{\circ} 56^{\prime} \mathrm{E}\right)$. To avoid bad smells, droppings were stored dry or frozen.

Sand was retained on $0.3-\mathrm{mm}$ sieves in some field samples collected on the lower-lying flats with coarser sediments. We overcame this problem by also sieving over a $0.5-\mathrm{mm}$ sieve 
and sorting both samples. All remaining sand fell through the $0.5-\mathrm{mm}$ sieve, and was separated from the rest in sub-samples of all that remained on the $0.3-\mathrm{mm}$ sieve, such as fragments of different mollusc prey species.

\section{RESULTS}

\section{Estimating prey size distributions}

\section{Bivalves}

In both Macoma and Cerastoderma, shell length is allometrically related to hinge+top height, but the relationships are almost linear in the size range usually taken by Knots (Fig. 1). The high $R^{2}$ values of $96 \%$ and $91 \%$ (although based on log-transformed variables) allow accurate estimation of shell length from hinge+top height. Analyses of covariance were carried out to test for differences between observers ( $n=7$ for Macoma and $n=4$ for Cerastoderma). With more than 70 hinges measured by each participant, the inter-observer effects on both slopes and intercepts were significant $(P<0.05)$. However, the additional variance explained by the observer effects was small enough $(1.1 \%$ in Macoma and $2.0 \%$ in Cerastoderma) to be unimportant. In contrast, rather large differences in the relationship between hinge height and shell length may exist between sites. A covariance analysis to test for the homogeneity of slopes and intercepts revealed a significant difference between the intercepts (but not slopes) for Cerastoderma from the Wadden Sea compared to those from the Somme estuary in northern France $(P<0.001$, additional explained variance $=$ $16.3 \%$; Fig. 1). The subsequent analyses of field samples of droppings revealed that the tops were absent from the majority of the identifiable Cerastoderma hinges, and therefore a separate prediction line for shell length on 'hinge-only' height was constructed (Fig. 1).

It is now necessary to consider if hinges from all size classes of molluscs have an equal chance of being found intact in the droppings. A rather variable proportion of the hinges of Macoma fed to Knots were relocated in the faeces (average $=45 \%$, SD $=18 \%$, range $=$ $16-71 \%, n=7)$, the rest having apparently broken up during the digestion process. In the case of Cerastoderma, $11 \%$ and $14 \%$ of hinges were relocated. Although reconstructed distributions (of ingested shell lengths in this case) are usually wider than the real distributions due to estimation scatter, there is no evidence that hinges of particular size classes were systematically lost (Fig. 2; each experi-

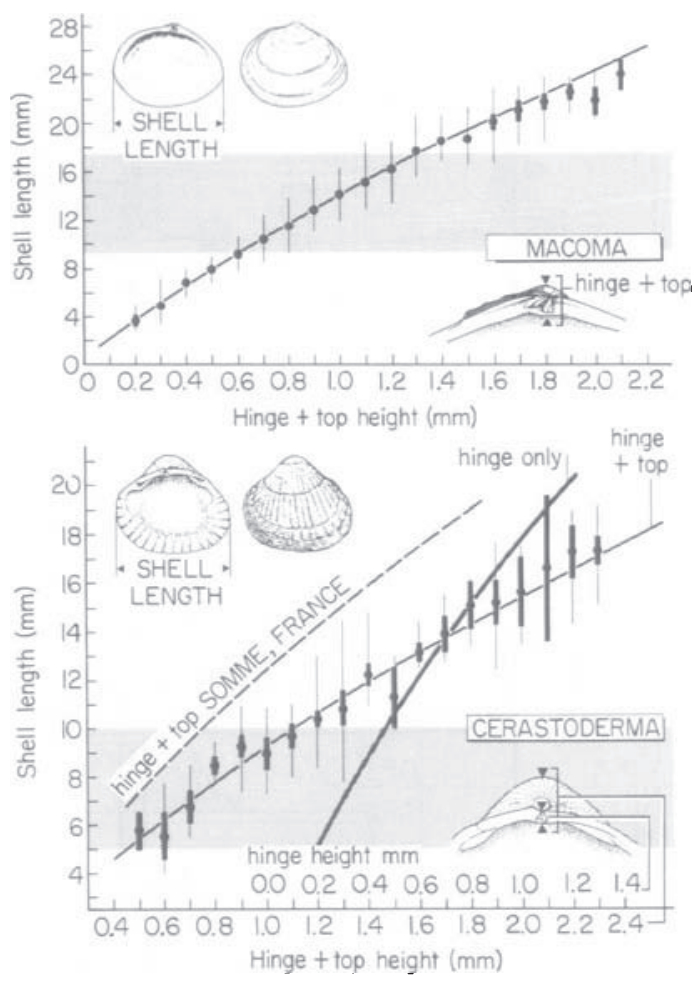

Figure 1. Estimating shell length (SL) from the height of hinge + top (HTH) or hinge only $(\mathrm{HH})$ in two common heterodont bivalve species which are fed upon by Knots in the Wadden Sea: Macoma balthica and Cerastoderma edule. The shaded area relative to the $y$-axis indicates which length classes are usually eaten by Knots according to the literature. Drawings of intact shells and hinges illustrate the measurements. Averages per hinge height category are presented with $95 \%$ confidence intervals (thick bars) and ranges (thin vertical lines). The doublelogarithmic regression lines are of specimens from the Wadden Sea only, and are based on measurements by 7 different observers of Macoma $\left(\mathrm{SL}=14.071 \mathrm{HTH}^{0.80}, R^{2}=0.96, n=668\right)$ and $4 \mathrm{ob}-$ servers of Cerastoderma (SL $=9.229 \mathrm{HTH}^{0.728}$, $R^{2}=0.91, n=304$ ). For Cerastoderma the (dotted) line for a population from the Somme Estuary, northern France, is also presented $(\mathrm{SL}=12.289$ $\mathrm{HTH}^{0.734}, \mathrm{R}^{2}=0.89, n=78$ ). The line to predict shell length on hinge height only was based on 72 measurements by one observer ( $\mathrm{SL}=17.579 \mathrm{HTH}^{0.735}$, $\left.R^{2}=0.94\right)$. 

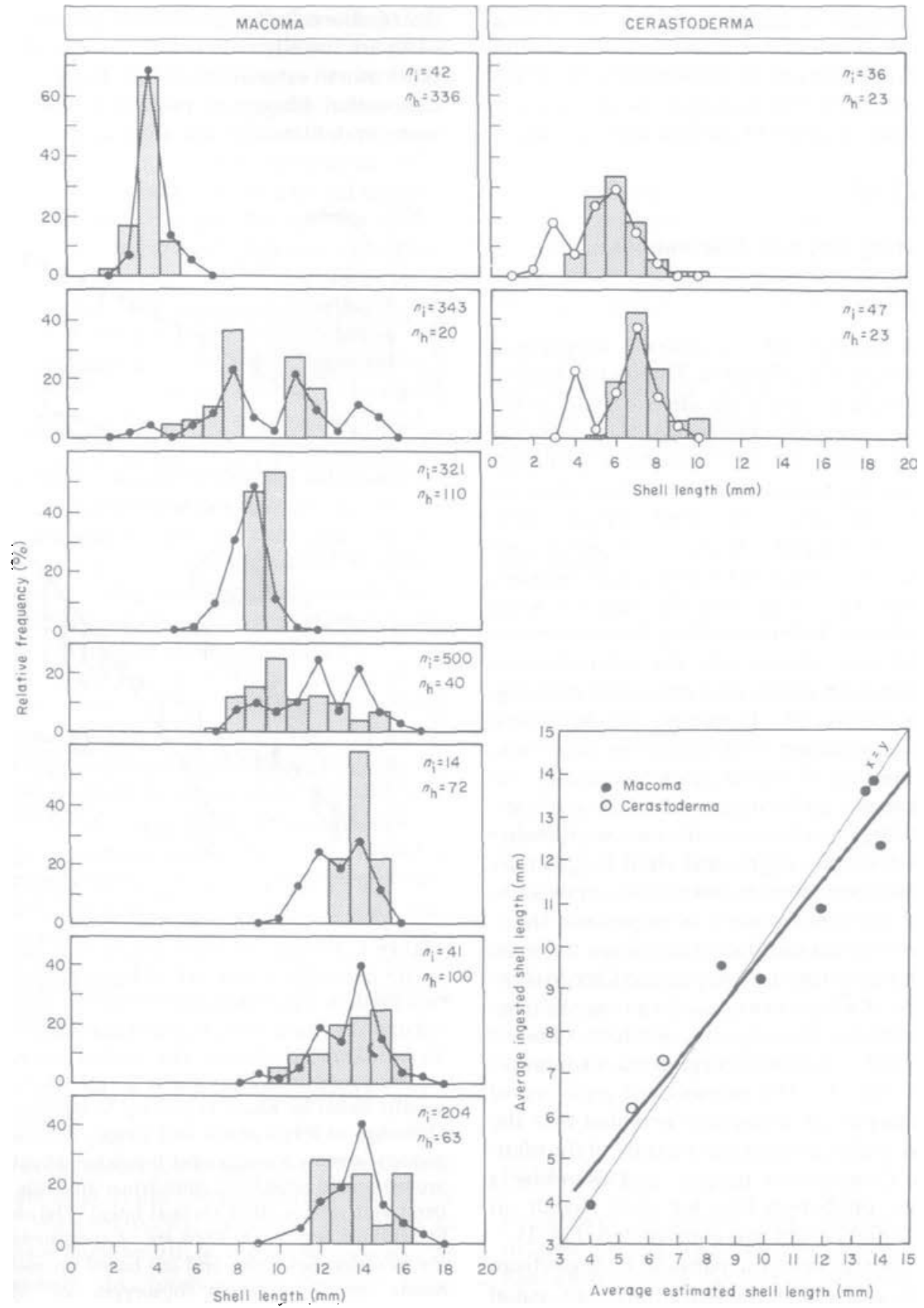

Figure 2. Correspondence between the shell length distribution of bivalves ingested by Knots (histograms) and the shell length distribution reconstructed on the basis of heights of hinges (filled and open circles) retrieved from their droppings (Fig. 1) in seven feeding experiments with Macoma and two with Cerastoderma. For each experiment, $n_{\mathrm{i}}$ indicates the sample size of measured bivalves out of those fed to the birds and $n_{\mathrm{h}}$ the total number of measured intact hinges found in the droppings. The panel at the bottom right gives a plot of the average ingested shell length as a function of average estimated shell length. Neither the intercept (1.308) nor the slope $(0.852)$ of the calculated regression equation represented by the thick line $\left(R^{2}=0.94, n=9\right)$ differed significantly from 0 and 1 respectively (i.e. $y=x$, thin line). 
ment provided one pair of data points and a Student's $t$-test for the 7 pairs of averages for Macoma yielded $t=0.235, P>0.10$ ). On the basis of a comparison between estimated and actual average shell lengths per experiment (Fig. 2), we conclude that the reconstruction of the sizes of ingested bivalves derived from the heights of intact hinges in the droppings, provides an unbiased estimate. However, we stress the necessity to use locality-specific regression lines in future studies.

Although the majority of individual droppings collected in the field contained only one prey species (T. Piersma, pers. obs.), some contained the remains of two or more species. It is possible that a combination of ingested shell types (e.g. Macoma together with Cerastoderma) could affect the relative presence in the droppings of measureable fragments of different-sized prey. Although we did not carry out the relevant experiments, we think this is unlikely because the force required to break the shells of the different molluse prey is very similar over the size ranges taken by Knots (T. Piersma, unpubl. data).

\section{Mudsnail Hydrobia}

Because the only measurable fragments of Hydrobia were slightly broken or intact (but empty and digested) shells, we tried to test whether such shells were representative of those ingested. The proportion of individual Hydrobia shells passing through the digestive tract of Knots unbroken was low but variable (average $=5.0 \%, \mathrm{sd}=6.6 \%$, range $=0.6-$ $23.0 \%, n=11$ ). Small shells were more likely to remain undamaged than large shells and we therefore fitted a log-linear regression of average ingested on average estimated shell height (Fig. 3). This conclusion is also implied by Zwarts \& Blomert's ${ }^{12}$ finding that half-broken Hydrobia, of which the width of the last whorl could be measured, were larger than those remaining intact in the stomach-contents of freeliving Knots (killed for experiments), and by a study of Common Eiders (droppings) which had fed on Periwinkles Littorina littorea (G.C. Cadée, pers. comm.). However, an analysis of covariance of the log-transformed average reconstructed shell height on non-transformed average ingested shell height (see Fig. 3), failed to indicate significant differences between reconstructed shell heights from intact and broken shells. Because the relationship between average shell height of Hydrobia in droppings and those ingested can be fairly well described by the log-linear model in Fig. 3, it is possible to estimate average ingested shell length from either broken or intact snails in the droppings.

When collecting droppings on mudflats

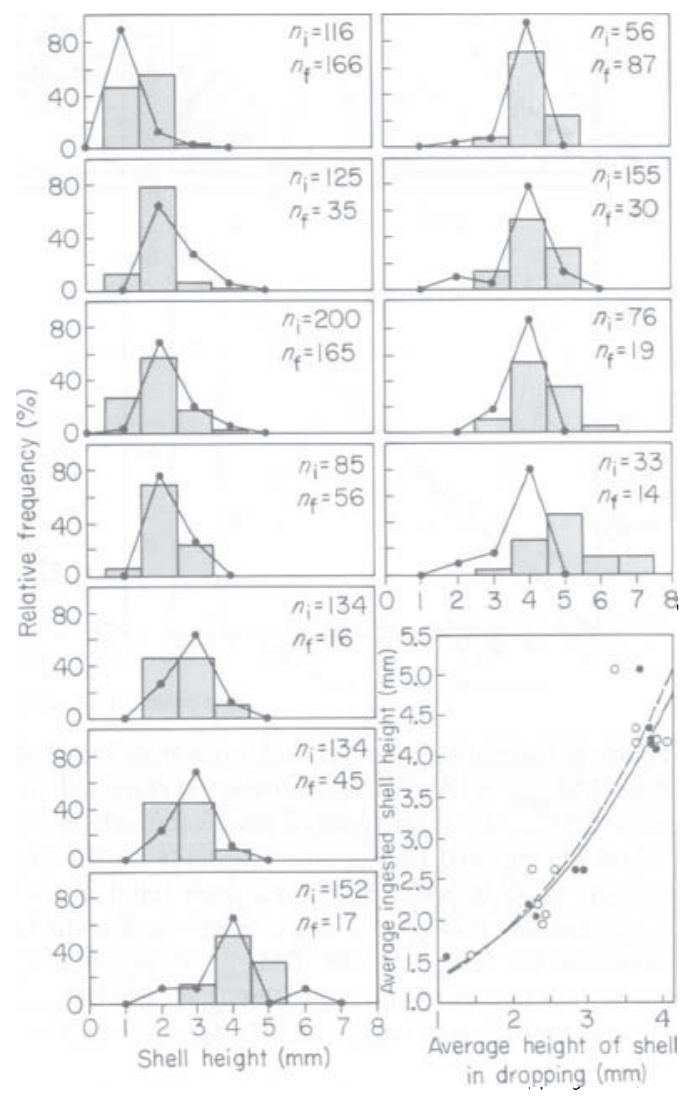

Figure 3. Correspondence between the shell height distribution of Hydrobia ulvae ingested by Knots (histograms) and the height distribution of measurable shells found intact in the droppings $(\bullet)$. For each of the 11 feeding trials, $n_{i^{\prime}}$ indicates the size of the measured sample out of a larger number of ingested snails and $n$. the total number of measured intact shells found in the droppings. Small Hydrobia shells more often remain intact than larger shells, and the plot at the bottom right indicates how average ingested shell height can be estimated from the intact Hydrobia found in faeces $\left(\bullet\right.$, unbroken line: $\left.\ln y=0.420 x-0.183, R^{2}=0.92, n=11\right)$, and from the height $(H)$ reconstructed from width (W; by the equation $\left.\mathrm{H}=1.7924 \mathrm{~W}^{1.326}, R^{2}=0.90, n=324\right)$ of broken shells (o, broken line: $\ln y=0.438 x-0.200, R^{2}=$ $0.85, n=11$; histograms not shown). 

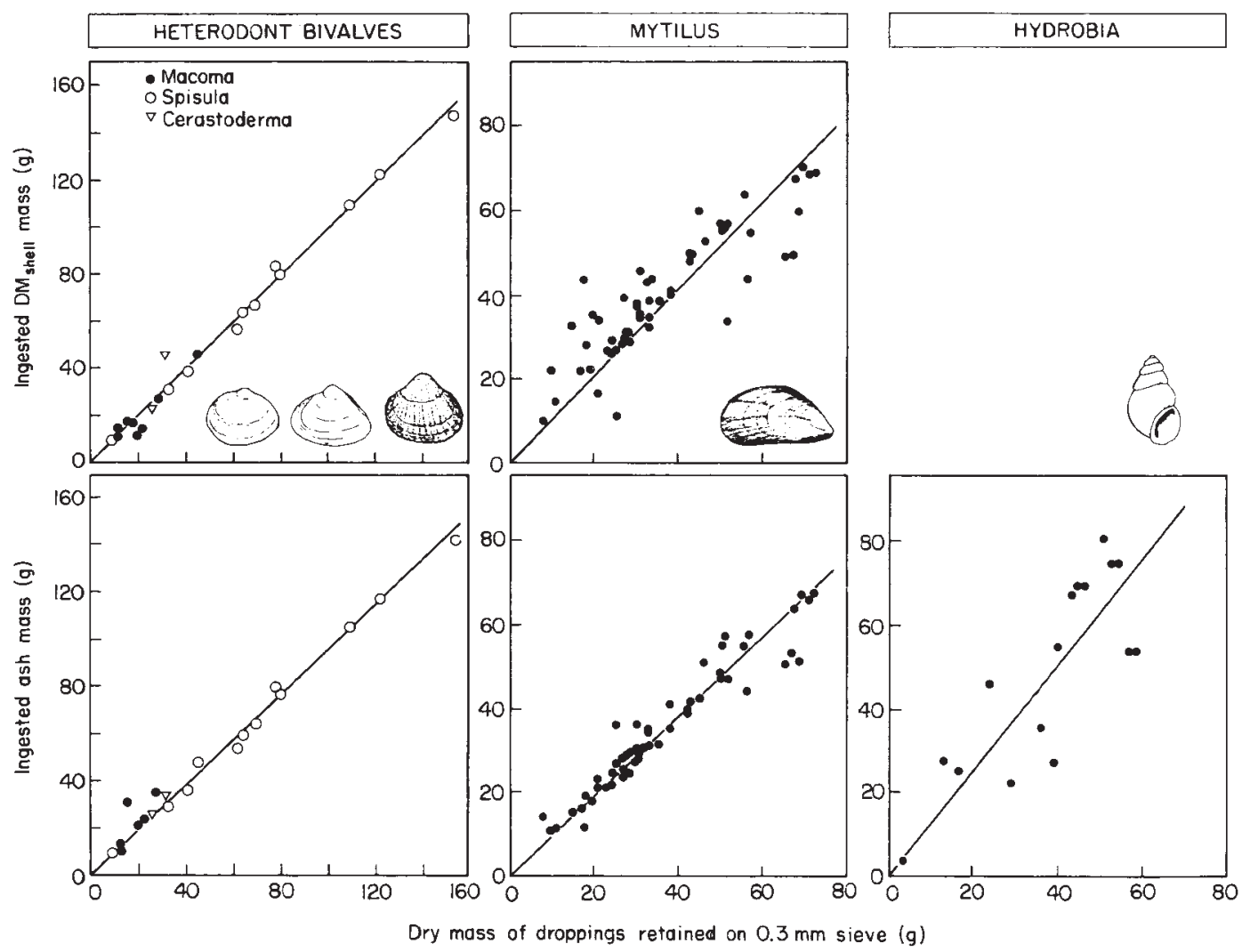

Figure 4. Estimating ingested shell mass from faecal samples. Ingested shell mass (expressed either as dry shell mass, $\mathrm{DM}_{\text {shells }^{\prime}}$ or indexed as ash mass) is regressed on the dry mass of the fraction of faeces retained on a 0.3-mm sieve $\left(\mathrm{DM}_{\mathrm{drop}}\right)$ for three types of prey commonly fed upon by Knots and one additional prey type (Spisula). No values for ingested $\mathrm{DM}_{\text {shell }}$ were available for the Mudsnail Hydrobia, because shell and meat are difficult to separate in gastropods. Each data point stands for a 24 -hr feeding trial with one bird. For each category the regression line through the origin is shown. For the heterodont bivalves Macoma, Cerastoderma and Spisula, the regression for $\mathrm{DM}_{\text {shell }}=0.987 \mathrm{DM}_{\text {drop }}\left(R^{2}=0.99 n=21\right)$ and for ash $\mathrm{DM}_{\text {ash }}=0.962 \mathrm{DM}_{\text {drop }}\left(R^{2}=0.98, n=\right.$ For Mytilus they are respectively $\mathrm{DM}_{\text {shell }}=1.040 \mathrm{DM}_{\mathrm{drop}}\left(R^{2}=0.63, n=57\right)$ and $\mathrm{DM}_{\text {ash }}=0.945 \mathrm{DM}_{\mathrm{drop}}\left(R^{2}=0.91, n=\right.$ 57 ), and for Hydrobia $\mathrm{DM}_{\mathrm{ash}}=1.267 \mathrm{DM}_{\mathrm{drop}}\left(R^{2}=0.65, n=16\right)$. See text for further details and covariance analyses.

with high densities of Hydrobia it is difficult to avoid the collection of some live animals. If the faeces are stored dry, the shells of digested Hydrobia which remain intact may be difficult to distinguish from accidentally collected live snails, and so the reconstruction on the basis of broken shells is generally preferable.

\section{Estimating diet composition}

The meat contents of molluscs, even of individuals of the same size, varies greatly with season and origin (see below; all species ${ }^{31}$, Mytilus, ${ }^{35-37}$ Macoma $^{38,39}$ ) and recent history (e.g. molluscs kept for some time in the laboratory have lowered values). Therefore, to estimate diet composition in terms of biomass, we have to use an inert and seasonally constant marker. The shell mass (or the total ash mass) of molluscs meets this criterion (T. Piersma, pers. obs.)..$^{40,41}$ Does the dry mass of the faeces retained on the $0.3-\mathrm{mm}$ sieve (DMdrop) correlate well with the ingested shell mass (DMshell) or ash mass (DMash)? Figure 4 shows strong relationships between ingested ash mass and $\mathrm{DM}_{\mathrm{drop}}$ in all three food categories, although they are somewhat weaker in the case of ingested shell mass and $\mathrm{DM}_{\text {drop }}$ in Mytilus. An analysis of covariance showed no effect of species on either intercept or slope of the re- 

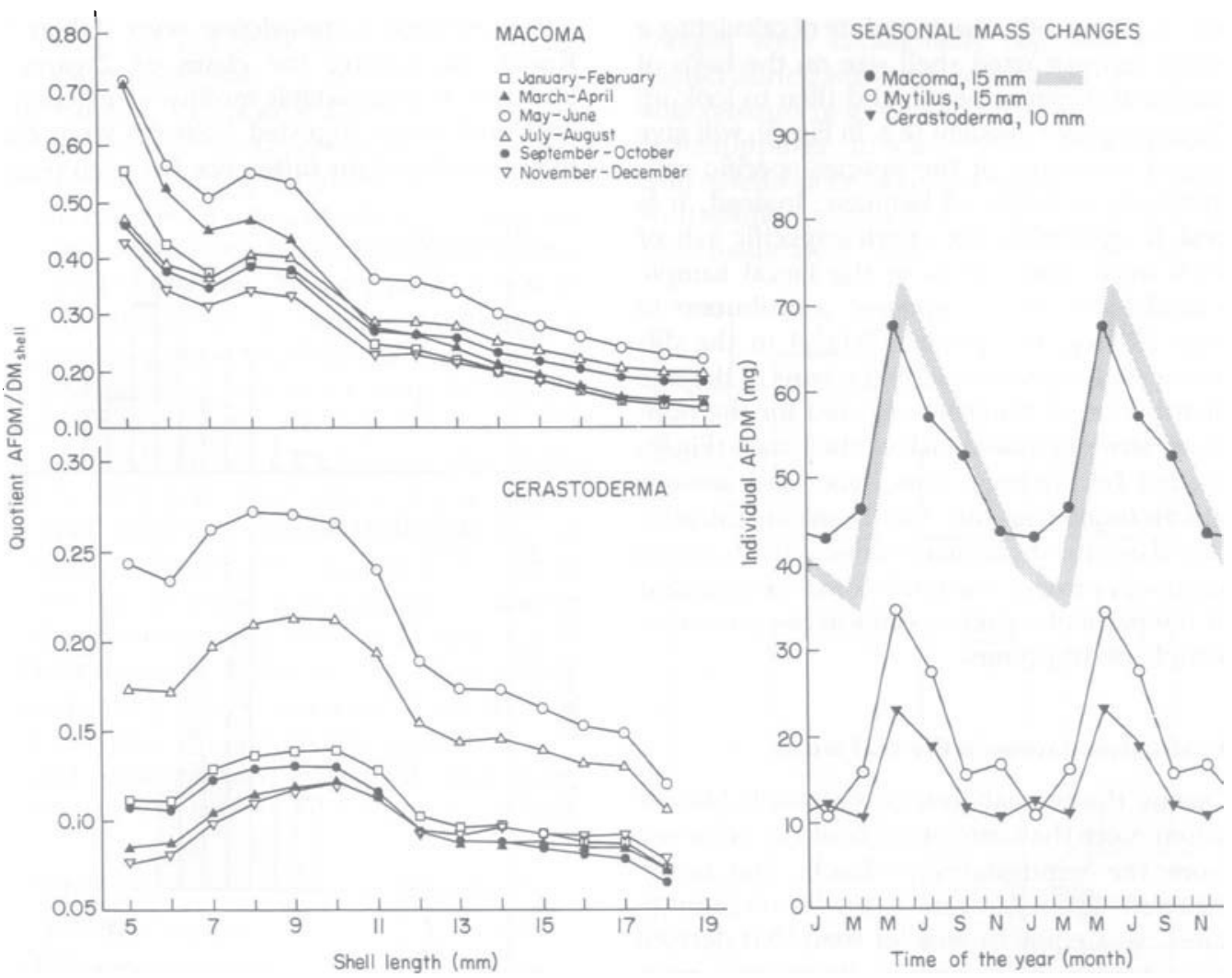

Figure 5. The effect of seasonal changes in biomass of the bivalve prey of Knots on the quotient $\alpha$ $\left(\mathrm{AFDM}_{\text {meat }} / \mathrm{DM}_{\text {shell. }}\right)$ used to reconstruct diet composition from dropping contents. The two left panels show the season (different lines) and size ( $x$-axis) dependent quotients for Macoma (top) and Cerastoderma (below). The panel on the right shows the seasonal changes in average mass of specific size classes of Macoma, Mytilus and Cerastoderma eaten by Knots, for bivalve populations from the Frisian Wadden Sea coast (lines; based on 11 years of data on biomass presented by Zwarts ${ }^{34}$ and shell mass by L. Zwarts (per. comm.)) and for Macoma from the Balgzand area (shaded; reconstructed from Fig. 3 in Beukema \& de Bruin ${ }^{39}$ so as to give the proportional changes in mass relative to the annual average mass for the Frisian Wadden Sea coast).

gressions of dry shell mass and ash mass on $\mathrm{DM}_{\text {drop }}$ within the group of heterodont bivalves. Although the slope of Mytilus for shell mass on $\mathrm{DM}_{\text {drop }}$ was higher than in the heterodont bivalves, and the slope of Hydrobia for ash on $\mathrm{DM}_{\text {drop }}$ was higher than in all the bivalves, covariance analyses failed to show significant effects of food type on intercepts or slopes of the regressions when all mollusc prey were considered together. We may therefore reliably estimate ingested ash mass from the faeces mass of mollusc-eating Knots retained on a $0.3-\mathrm{mm}$ sieve by the equation $\mathrm{DM}_{\text {ash }}=$ $0.977 \mathrm{DM}_{\mathrm{drop}}\left(R^{2}=0.86\right)$. More prudently one could also use separate equations for bivalves and Hydrobia if the remains in the droppings attributable to the different prey types are separated (see below and Table 1). For Knots feeding on bivalves only, ingested shell mass can be estimated from $\mathrm{DM}_{\text {drop }}$ by the equation $\mathrm{DM}_{\text {shell }}=0.994 \mathrm{DM}_{\mathrm{drop}}\left(R^{2}=0.87\right)$.

In order to estimate diet composition with respect to biomass we now have to compute the ingested AFDM meat $_{\text {(or AFDM }}$ tot: compulsory in Hydrobia) on the basis of estimated ash or shell mass by multiplying the latter mass by the ratio between AFDM and ash or shell mass (if $\mathrm{AFDM}_{\text {meat }} / \mathrm{DM}_{\text {shell }}=\alpha$, then

$\alpha \mathrm{DM}_{\text {shell }}=\mathrm{AFDM}_{\text {meat }}$ ). The $\alpha$-quotient varies with season and shell length (Fig. 5). The existence of a non-linear relationship between the shell size and shell mass is a further complica- 
tion. Consequently, the procedure of calculating a mean reconstructed shell size on the basis of fragment measurements, and then to look up the appropriate quotient (e.g. in Fig. 5), will give biased estimates of the species-specific contributions to ingested biomass. Instead, it is best to apportion the species-specific ash or shell mass equivalents of the faecal sample (calculated from the species' contribution to total $\mathrm{DM}_{\text {drop, }}$ i.e. partial $\mathrm{DM}_{\mathrm{drop}}$ ) to the different shell size classes (on the basis of the size distribution of hinges), adjusted for the nonlinear size-dependent ash or shell mass (Fig. 6: shaded histograms). Site-, size- and seasonspecific $\alpha$-quotients can then be used to calculate size-class specific biomass values which, when summed, provide the total biomass equivalent of the particular prey species in the particular sample of droppings.

\section{Evaluation: faeces in the real world}

During the two laboratory trials with Macoma when more than one hinge could be retrieved from the regurgitates of Knots, the reconstructed size of Macoma derived from regurgitates, was equal or smaller than that derived from hinges in droppings. Respective mean ( \pm sd) shell lengths from regurgitates were $9.38 \pm 2.27 \mathrm{~mm}(n=15)$ and $4.93 \pm 0.67 \mathrm{~mm}(n=8)$, and from droppings $11.85 \pm 3.02 \mathrm{~mm}(n=49)$ and $4.99 \pm 1.58 \mathrm{~mm}(n=23)$; the differences are not statistically significant at the 5\%-level (Student's t-test).

A comparison of simultaneously collected field samples of droppings and regurgitates (it is hard to call them pellets in view of their soft and slimy appearance) showed the latter to contain the remains of significantly larger Macoma than droppings (Fig. 7). Thus, regurgitates yield overestimates of the size of Macoma. This confirms the results of Goss-Custard et al. ${ }^{9}$ but contrasts with the findings in the laboratory (above) where droppings and regurgitates yielded equal sizes. However, the range of available and ingested shell lengths, and therefore the chances of finding a bias, was much more limited in the laboratory experiments than in the field. We advise the use of droppings to obtain unbiased estimates of ingested Macoma.

The sizes of ingested molluscs (Fig. 6) show that flat-shelled Macoma of greater length than convex-shaped Cerastoderma were taken by Knots, supporting the claim of Zwarts \& Blomert ${ }^{12}$ that ingestable mollusc size depends on slenderness. Ingested Hydrobia were relatively small and the difference between recon-

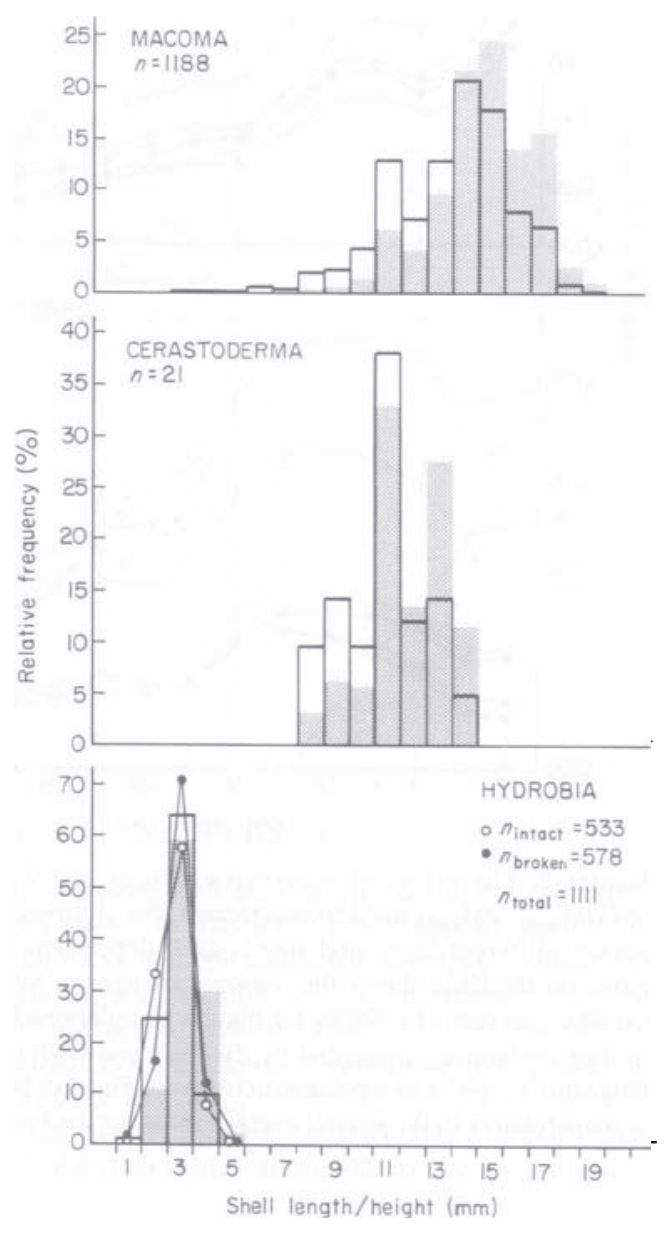

Figure 6. Frequency distributions of the sizes of three mollusc species ingested by Knots near Griend in the western Wadden Sea in August-October 1988. Size distributions were reconstructed on the basis of shell remains as outlined in this paper. For Hydrobia the histogram presents reconstructed shell heights on the basis of both broken and intact shells. The line histograms give the frequency distributions on the basis of measured fragment numbers, the shaded histograms show the relative frequency distributions when numbers were weighted for sizespecific shell mass. Respective average lengths on the basis of unweighted and weighted (shaded) distributions are 13.1 and $14.7 \mathrm{~mm}$ for Macoma, 10.9 and $11.7 \mathrm{~mm}$ for Cerastoderma and 2.8 and $3.2 \mathrm{~mm}$ for Hydrobia. 
structions on the basis of intact and broken shells was negligible.

In August, Knots near Griend fed only on Macoma (Fig. 8), Cerastoderma being an unimportant prey. During the course of the autumn season the contribution of Macoma to the diet declined, and by October almost the entire diet consisted of Hydrobia. This dramatic change in food spectrum coincides with a withdrawal of Macoma to a greater depth below the surface of the sediment (T. Piersma, unpubl. data). Hyrdobia was available throughout but was only fed upon by Knots when the densities of available Macoma dropped. The biomass equivalent of the shell fragments found in the droppings changed little during the study period (from 29 $\mathrm{mg}$ ash free dry mass in August and September to $38 \mathrm{mg}$ ash free dry mass in October). It is evident from Fig. 8 that Hydrobia has a more favourable quotient between biomass and shell/ash mass than the bivalve species.

Field observations suggested that small crabs Carcinas maenas and shrimps Crangon

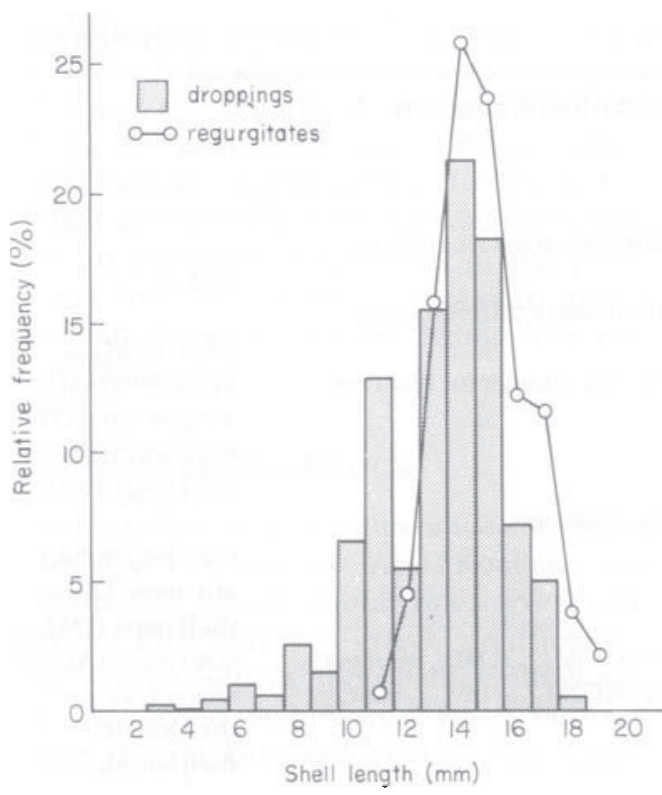

Figure 7. Comparison of the length distributions of Macoma balthica reconstructed from the 'hinge + top's retrieved from 550 droppings and from 50 regurgitates. All ejecta were collected at a high tide roost on Griend on 8 August 1988. Mean ( $\pm s d$ ) reconstructed shell lengths from the regurgitates were $14.77 \pm 1.64 \mathrm{~mm}(n=$ $139)$ and from droppings $13.11 \pm 2.42 \mathrm{~mm}(n=758)$. This difference is statistically significant (Student's $t$-test, $P<0.001)$. crangon were occasionally captured and ingested during early autumn. Indeed, recognizable remains (e.g. pincer parts) were found in the droppings. In view of the comparatively thin 'shells' of crustaceans (cf. molluscs), their contribution to faecal dry mass is likely to be underestimated. The methods described in

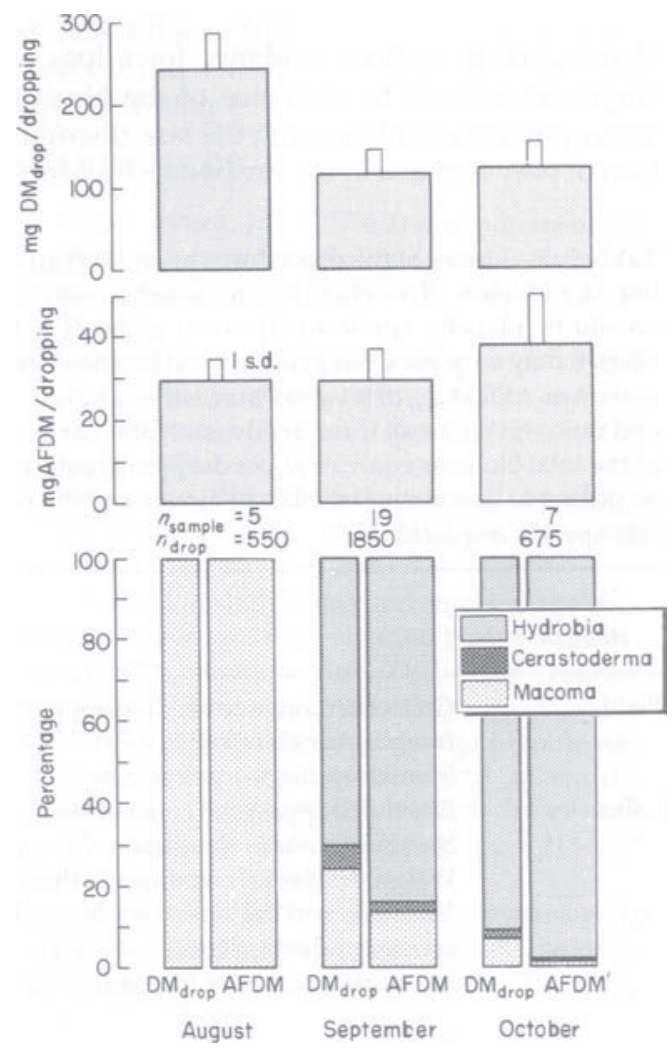

Figure 8. Seasonal changes in the diet composition of Knots foraging near Griend in the western Wadden Sea in August-October 1988 as reconstructed from samples of droppings (one sample usually contained 100 droppings). The reconstruction was based on shell size specific calculations (as explained in 'Estimating diet composition'). Diet composition is ex-

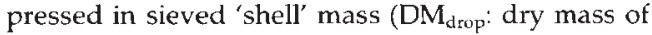
fragments in droppings retained on a $0.3-\mathrm{mm}$ sieve; left column) and in ash free dry mass $\left(\right.$ AFDM $_{\text {meat }}$ for bivalves, $A F D M_{\text {total }}$ for Hydrobia; right column). The average $( \pm \mathrm{sd}$, for the listed number of faecal samples) mass of sieved 'shell' fragments and the calculated biomass equivalent per dropping (i.e. $\mathrm{AFDM}_{\text {meat }}$ for bivalves and AFDM $\mathrm{Atal}_{\text {tol }}$ for Hydrotria) for each of the three periods are given in the two top rows. Note that the $\alpha$-quotients used are empirical for the appropriate site and season, and somewhat lower than those in Fig. 5. 
this paper would be inappropriate in cases where crustaceans contribute significantly to the diet of Knots in intertidal areas (a situation we have not yet encountered, and which has not been described in Europe).

\section{DISCUSSION: DID PREVIOUS STUDIES GET IT RIGHT?}

Because there was no evidence for a loss of fragments related to shell size of the bivalve prey, previous studies using the size distribution of prey remains in the droppings to recon- struct the diet of Knots ${ }^{10,12}$ are probably valid. Although estimating the size distribution of ingested Hydrobia does present a problem (Fig. 3), this prey species has not been of great importance in any of the published studies.

This study therefore provides a post-hoc validation of earlier contributions, and also extends the possible use of droppings. The method allows a fairly accurate description of the diet in terms of biomass, as well as providing an indication of ingested biomass per dropping (Fig. 8). In combination with defecation rates, estimated ingested biomass equiva-

Table 1. Summary of the procedures to arrive at an estimate of diet composition on the basis of faeces in Knots feeding on molluscs. Note that the presented equations relating sieved dropping mass to ingested shell or ash mass should be globally applicable (printed in bold), whereas others (i.e. those relating faecal fragment size to shell length) may vary between geographical locations; those listed refer to the western Wadden Sea (see text). The estimation of $\mathrm{AFDM}_{\text {meat }}$ of bivalves may either be done via ash mass and ratio (only given for Macoma) or via shell mass and ratio (given for all three bivalves). Note that in the case of bivalve species the best (most unbiased) estimations of the total biomass equivalent per dropping requires the use of the size-specific contributions to DM $\mathrm{drop}_{\text {(calculated }}$ according to the relative number of hinges and the non-linear relationship between size and shell/ash mass) and the size-specific $\alpha$-quotients

\begin{tabular}{|c|c|c|}
\hline $\begin{array}{c}\text { Working } \\
\text { environment }\end{array}$ & Procedure & $\begin{array}{c}\text { Measured/estimated } \\
\text { parameters }\end{array}$ \\
\hline
\end{tabular}

Field

Collect certain number of droppings on area where Knots were foraging for $45 \mathrm{~min}$ or longer Store droppings dry or frozen

$n_{\mathrm{drop}}$

Laboratory Dry the droppings to constant mass

Sort over $0.3-\mathrm{mm}$ sieve to remove sand, dirt \& smallest fragments

Weigh the fraction retained on the sieve

Manually sort the sieved fraction in fragments from different prey

species under binocular and weigh

Measure identifiable fragments with ocular micrometer for bivalves:

for Hydrobia:

Desk Compute prey size (distribution) and diet parameters:

Macoma: $\quad$ SL $=14.071 \mathrm{HTH}^{0.801}$

$\mathrm{DM}_{\mathrm{ash}}=0.977 \mathrm{DM}_{\mathrm{drop}}$

$\mathrm{DM}_{\text {shell }}=0.994 \mathrm{DM}_{\mathrm{drop}}$

$\mathrm{AFDM}_{\text {meat }}=\mathrm{DM}_{\mathrm{ash}} \cdot$ correct $\mathrm{AFDM}_{\text {meat }} / \mathrm{DM}_{\text {ash }}$ quotient

Cerastoderma: $\quad \mathrm{SL}=17.579 \mathrm{HH}^{0.735}$

$\mathrm{AFDM}_{\text {meat }}=\mathrm{DM}_{\text {shell }} \bullet$ correct $\mathrm{AFDM}_{\text {meat }} / \mathrm{DM}_{\text {shetl }}$ quotient

$\mathrm{SL}=9.299 \mathrm{HTH}^{0.728}$

$\mathrm{DM}_{\text {shell }}=0.994 \mathrm{DM}_{\text {drop }}$

Mytilus: $\quad$ not possible

$\mathrm{DM}_{\text {shel1 }}=0.994 \mathrm{DM}_{\mathrm{drop}}$

$\mathrm{AFDM}_{\text {meat }}=\mathrm{DM}_{\text {shell }} \bullet$ correct $\mathrm{AFDM}_{\text {meat }} / \mathrm{DM}_{\text {shell }}$ quotient meat mass

Hydrobia: $\quad \mathrm{H}=1.729 \mathrm{~W}^{1.326}$ for broken shells

In $\mathrm{SL}=0.438 \mathrm{H}-0.200$

$\mathrm{DM}_{\text {ash }}=1.267 \mathrm{DM}_{\text {drop }}$

$\mathrm{AFDM}_{\text {total }}=\mathrm{DM}_{\mathrm{ash}} \cdot$ correct $\mathrm{AFDM} \mathrm{total}_{\text {tas }} / \mathrm{DM}_{\text {ash }}$ quotient
$\mathrm{DM}_{\mathrm{drop}}$

partial DM drop

hinge height $(\mathrm{HH})$

hinge+top (HTH)

shell widths (W)

shell heights $(\mathrm{H})$

shell length (SL)

ash mass $\left(\mathrm{DM}_{\mathrm{ash}}\right)$

shell mass (DM $\left.{ }_{\text {shell }}\right)$

meat mass (AFDM meat $_{\text {. }}$ )

meat mass

shell length

shell length

shell mass

meat mass

shell length

shell mass

shell height $(\mathrm{H})$

ingested av.length

ash mass $\left(\mathrm{DM}_{\mathrm{ash}}\right)$

tot.AFDM (AFDM total $)$ 
lents' per dropping can be used to estimate biomass intake rates. ${ }^{12}$ Whether the much smaller biomass equivalents of the droppings of Knots in New Zealand ${ }^{10}$ compared to those in the Wadden Sea (Fig. 8), ${ }^{12}$ are due to differences in defecation or intake rates remains to be found out. In principle, however, the measurement of droppings contents in combination with defecation rates could provide fairly sensitive estimates of intake rates, even in situations where individual prey are too small to be observed when ingested.

\section{CONCLUSION: INSTRUCTIONS SUMMARIZED}

The essence of this paper is summarized in Table 1, which lists the procedural steps and equations needed to quantify the diet of Knots in the estuaries of north-west Europe. Because the procedures are straightforward and generally applicable, similar schemes can be developed for Knots foraging at other locations and on different prey types, and for other intertidal benthic predators. Note that, at least for Knots, it is not necessary to redevelop all the equations required to estimate ingested ash or dry shell mass from $\mathrm{DM}_{\text {drop }}$ (which would basically require a repeat of this study). All that are needed are the relevant laboratory data on the mass-composition of the preyspecies (the AFDM/DM ${ }_{\text {shell }}$ quotients) and a check on the equations predicting their size from fragments.

\section{ACKNOWLEDGMENTS}

This study has been a co-operative enterprise in which Jeffrey Samuels, Anita Koolhaas and Jan van Gils played critical roles. We thank them for their efforts in carrying out feeding trials and measuring thousands of molluscs and fragments, and Martin Poot, Bernard Roelen, Ingrid Tulp and Yvonne Verkuil for doing their share. Rinke Hoekstra and Georg Nehls helped to collect droppings near Griend. The crews of the Griend, the Navicula and the Phoca ensured that natural Knot prey were captured and people transported. The Vereniging tot behoud van Natuurmonumenten in Nederland granted permission to do the fieldwork on Griend. Leo Zwarts was our enthusiastic 'telephonic vademecum' who also made many data points available. Jaap van der Meer assisted with statistics. We thank our colleagues in the
Coastal Systems group at NIOZ for providing help and for their tolerance, and Ben Helming and Rients Hofstra of the van Hall Instituut in Groningen for allowing A.D. to participate until completion. Dick Visser meticulously prepared the figures. Finally, the constructive remarks of John Goss-Custard, Lukas Jenni, Gerhard Cadée, Jan J. Beukema, Leo Zwarts, Anita Koolhaas, Nick Davidson, Georg Nehls, referees and editor have helped to get this paper into shape.

\section{REFERENCES}

1. Goss-Custard, J.D. (1970) The responses of redshank (Tringa totanus (L.)) to spatial variations in the density of their prey. J. Anim. Ecol. 39, 91-113.

2. Goss-Custard, J.D. (1977) Responses of redshank, Tringa totanus, to the absolute and relative densities of two prey species. J. Anim. Ecol. $46,867-874$.

3. Sutherland, W.J. (1982) Do oystercatchers select the most profitable cockles? Anim. Behav. 30, 857-861.

4. Zwarts, L. (1980) Intra- and interspecific competition for space in estuarine bird species in a one-prey situation. Acta XVII Congr. Internat. Ornithol. (Berlin), pp. 1045-1050.

5. Meire, P. (1987) Foraging behavior of some wintering waders: prey selection and habitat distribution. In Foraging Behavior (eds A.C. Kamil, J.R. Krebs \& H.R. Pulliam), pp. 215-237. Plenum Press, New York.

6. Piersma, T. (1987) Production by intertidal benthic animals and limits to their predation by shorebirds: a heuristic model. Mar. Ecol. Prog. Ser. 38, 187-196.

7. Swennen, C., Leopold, M.F. \& De Bruijn, L.L.M. (1989) Time-stressed oystercatchers, Haematopus ostralegus, can increase their intake rate. Anim. Behav. 38, 8-22.

8. Prater, A.J. (1972) The ecology of Morecambe Bay. III. The food and feeding of Knot (Calidris canutus) in Morecambe Bay. J. Appl. Ecol. 9, 179-194.

9. Goss-Custard, J.D., Jenyon, R.A., Jones, R.E., Newbery, P.E. \& Williams, R.LeB. (1977) The ecology of the Wash. II. Seasonal variation in feeding conditions of wading birds (Charadrii). J. Appl. Ecol. 14, 701-719.

10. Piersma, T. (1991) Red Knots in New Zealand eat molluscs too: preliminary diet observations at Miranda, Firth of Thames and Farewell Spit in November 1990. Stilt, 19, 30-35.

11. Nehls, G. (1992) Food selection of Knots Calidris canutus in the Wadden Sea: the importance of seasonal and annual variation of food availability. Wader Study Group Bull. (in press).

12. Zwarts, L. \& Blomert, A.-M. (1992) Why Knot 
(Calidris canutus) take medium-sized Macoma balthica when six prey species are available? Mar. Ecol. Prog. Ser. 83, 113-128.

13. Zwarts, L., Blomert, A.-M. \& Wanink, J.H. (1992) Annual and seasonal variation in the food supply harvestable by Knot Calidris canutus staging in the Wadden Sea in late summer. Mar. Ecol. Prog. Ser. 83, 129-139.

14. Gerritsen, A.F.C. (1988) Feeding techniques and the anatomy of the bill in sandpipers (Calidris). PhD thesis, University of Leiden.

15. Goss-Custard, J.D. (1973) Current problems in studying the feeding ecology of estuarine birds. Coastal Ecology Research Paper Nr. 4, Nature Conservancy, Norwich.

16. Worrall, D.H. (1984) Diet of the Dunlin Caldris alpina in the Severn estuary. Bird Study, 31, 203212.

17. Pienkowski, M.W., Ferns, P.N., Davidson, N.C. \& Worrall, D.H. (1984) Balancing the budget: measuring the energy intake and requirements of shorebirds in the field. In Coastal Waders and Wildfowl in Winter (eds P.R. Evans, J.D. Goss-Custard \& W.G. Hale), pp. 29-56. Cambridge University Press, Cambridge.

18. Ie V dit Durrell, S.E.A. \& Kelly, C.P. (1990) Diets of Dunlin Calidris alpina and Grey Plover Pluvialis squatarola on the Wash as determined by dropping analysis. Bird Study, 37, 44-47.

19. Green, R.E. (1978) Factors affecting the diet of farmland skylarks (Aves: Motacillidae). J. Anim. Ecol. 46, 37-57.

20. Green, R.E. (1984) The feeding ecology and survival of partridge chicks (Alectoris rufa and Perdix perdix) on arable farmland in East Anglia. J. Appl. Ecol. 21, 817-830.

21. Duffy, D.C. \& Jackson, S. (1986) Diet studies of seabirds: a review of methods. Colonial Waterbirds 9, 1-7.

22. Green, R.E. \& Tyler, G.A. (1989) Determination of the diet of the stone curlew (Burhinus oedicnemus) by faecal analysis. J. Zool., Lond. 217, 311-320.

23. Jenni, L., Reutimann, P. \& Jenni-Eiermann, S. (1990) Recognizability of different food types in faeces and in alimentary flushes of Sylvia warblers. Ibis, 132, 445-453.

24. Major, R.E. (1990) Stomach flushing of an insectivorous bird: an assessment of differential digestibility of prey and the risks to birds. Aust. Wildl. Res. 17, 647-657.

25. Young, E.C. (1990) Diet of the south polar skua Catharacta maccormicki determined from regurgitated pellets: limitations of a technique. Polar Rec. 26, 124-125.

26. Zwarts, L. \& Wanink, J. (1984) How oystercatchers and curlews successively deplete clams. In Coastal Waders and Wildfowl in Winter (eds P.R. Evans, J.D. Goss-Custard \& W.G. Hale), pp. 69-83. Cambridge University Press, Cambridge.
27. Zwarts, L. (1985) The winter exploitation of fiddler crabs Uca tangeri by waders in GuineaBissau. Ardea, 73, 3-12.

28. Piersma, T. (1986) Foraging behaviour of Terek Sandpipers Xenus cinereus feeding on Sandbubbling Crabs Scopimera globosa. J. Orn. 127, 475-486.

29. Esselink, P. \& Zwarts, L. (1989) Seasonal trend in burrow depth and tidal variation in feeding activity of Nereis diversicolor. Mar. Ecol. Prog. Ser. 56, 243-254.

30. Zwarts, L. \& Wanink, J. (1989) Siphon size and burying depth in deposit-and suspension-feeding benthic bivalves. Mar. Biol. 100, 227-240.

31. Zwarts, L. (1991) Seasonal variation in body weight of the bivalves Macoma balthica, Scrobicularia plana, Mya arenaria and Cerastoderma edule in the Dutch Wadden Sea. Neth. J. Sea Res. 28, 231-245.

32. Nyström, K.G.K., Pehrsson, O. \& Broman, D. (1991) Food of juvenile Common Eiders (Somateria mollissima) in areas of high and low salinity. Auk, 108, 250-256.

33. Nehls, G. (1991) Bestand, Jahresrhythmus und Nahrungsökologie der Eiderente, Somateria mollissima, L. 1758, im Schleswig-Holsteinischen Wattenmeer. Corax, 14, 146-209.

34. Cadée, G.C. (1988) Levende Wadslakjes in Bergeend faeces. Corr. Blad Ned. Malac. Ver. 243/ 4, 443-444.

35. Dare, P.J. \& Edwards, D.B. (1975) Seasonal changes in flesh weight and biochemical composition of Mussels (Mytilus edulis L.) in the Conwy estuary, north Wales. J. Exp. Mar. Biol. Ecol. 18, 89-97.

36. Pieters, H., Kluytmans, J.H., Zandee, D.I. \& Cadée, G.C. (1980) Tissue composition and reproduction of Mytilus edulis in relation to food availability. Neth. J. Sea Res. 14, 349-361.

37. Cayford, J.T. \& Goss-Custard, J.D. (1990) Seasonal changes in the size selection of mussels, Mytilus edulis, by oystercatchers, Haematopus ostralegus: an optimality approach. Anim. Behav. 40, 609-624.

38. Chambers, M.R. \& Milne, H. (1975) The production of Macoma balthica (L.) in the Ythan estuary. Est. Coast. Mar. Sci. 3, 443-455.

39. Beukema, J.J. \& De Bruin, W. (1977) Seasonal changes in dry weight and chemical composition of the soft parts of the tellinid bivalve Macoma balthica in the Dutch Wadden Sea. Neth. J. Sea Res. 11, 42-55.

40. Beukema, J.J. (1980) Calcimass and carbonate production by molluscs on the tidal flats in the Dutch Wadden Sea: I. the tellinid bivalve Macoma balthica. Neth. J. Sea Res. 14, 323-338.

41. Beukema, J.J. (1982) Calcimass and carbonate production by molluscss on the tidal flats in the Dutch Wadden Sea: II. the edible cockle Cerastoderma edule. Neth. J. Sea Res. 15, 391-405. 